\title{
DEA-BASED INTEGRATED RELATIONSHIP OF RETURNS TO SCALE - AN APPLICATION TO ROAD MAINTENANCE IN TAIWAN
}

\author{
Gang Lee ${ }^{1}$, Ming-Miin $\mathbf{Y u}^{2}$, Lung-Chuang Wang ${ }^{3}$ \\ ${ }^{1,3}$ Department of Civil Engineering, National Taipei University of Technology, \\ Chung-hsiao E. Rd., Taipei, 10608, Taiwan, ROC \\ ${ }^{2}$ Department of Transportation Science, National Taiwan Ocean University, \\ Keelung 202, Taiwan, ROC \\ E-mail:2yumm@mail.ntou.edu.tw (corresponding author) \\ Received 24 Oct. 2010; accepted 01 Aug. 2011
}

\begin{abstract}
An Integrated Relationship of Returns to Scale (IRRS) associated with multiple-stage Data Envelopment Analysis (DEA) is proposed for identifying the returns to scale (RTS) among decision-making units (DMUs) appropriately and accurately. The validity and feasibility of the proposed method is tested by using 31 case studies on highway maintenance and construction offices based on the data provided by the Directorate General of Highways (Taiwan). The results show that the multi-stage DEA method with IRRS is more useful than the traditional single-stage DEA for evaluating the status of RTS for each DMU. Among the 31 units evaluated, 14 units are categorized as having increasing returns to scale, 4 have decreasing returns to scale, and no unit has constant returns to scale; the returns for the remaining 13 units cannot be determined.
\end{abstract}

Keywords: integrated relationship of returns to scale; data envelopment analysis; slack-based measure; highway maintenance.

\section{Introduction}

Taiwan, which is surrounded by seas, is humid and rainy, with frequent typhoons and earthquakes. The harsh environment along with severe traffic overloads causes the highway system to suffer rapid aging and deterioration. The Department of Highways, Ministry of Transportation and Communication, is currently maintaining 8000 miles of primary and secondary roads, 4000 bridges, and 200 tunnels. The Directorate General of Highways (DGH) encompasses 5 Maintenance and Construction Offices (MCO) and 31 District Works Sections (DWS). The latter are the most important units to implement highway maintenance, including bridge inspection and repairing, highway re-surfacing, and other road maintenance operations. Their performance is of great importance to maintaining the quality of provincial and regional road systems.

The construction of new highway systems in Taiwan is currently slowing down, whereas the role of maintaining and managing the highway system is becoming more important. Evaluation of the highway maintenance accomplishments of each DWS is based on not only the quality of service but also the effective allocation of limited resources such as personnel, equipment and budget. Hence, performance evaluation needs to be carried out for effectively evaluating the highway maintenance accomplished by each DWS (Tatari, Skibniewski 2006).
Among the various methods, the DEA method has evolved into a specific industrial field (e.g., airports, harbors, hotels, hospitals, banks, etc.) (Cook, Zhu 2007; Yu, Lee 2009), because it has been widely applied in the various fields for developing theoretical bases and practical methods. DEA uses observed input and output data to construct the best practice frontier. The application of DEA for evaluating the performance of an organization depends on the development of an appropriate model. This method is widely applied to estimating production frontiers and evaluating the relative efficiency of decision making units (DMUs). Once the models are determined, application of DEA in an organization is relatively simple. Tone and Sahoo (2006) mentioned that many public and private sectors use DEA efficiency, in technical efficiency and returns to scale (RTS) measurement, to measure the production efficiency among their organizations. The assessment of technical efficiency helps with proper selection of inputs, whereas the returns to scale measurement assists in recommendations of restructuring strategies for any sector.

Estimating RTS is one of several curious issues when applying DEA, and a number of approaches have been proposed for this purpose. RTS can provide useful information to decide whether a technically efficient DMU can improve its productivity by resizing the scale of its operations (Soleimani-damaneh et al. 2010). In this paper a new concept of RTS in the presence of the relationship between different production stages in a given 
operational process is proposed for obtaining results that are practically useful to assist in the DEA application.

The Slack-based Measure DEA (SBM-DEA) model is used to establish the production frontier under Constant Returns to Scale (CRS), and Variable Returns to Scale (VRS) for evaluating the Technical Efficiency (TE), and Pure Technical Efficiency (PTE) of the production and service stages. The results are further used for calculating the Scale Efficiency (SE) of the two stages, and for determining the status of RTS of the two stages of DMUs with the Integrated Relationship of Returns to Scale (IRRS) that has been developed in this research.

Due to the fixed intermediate products between the production stage and service stage, performance can be more appropriately evaluated using the two-stage DEA method with IRRS. Hence, the two-stage DEA with IRRS method is proposed to identify the RTS for each DMU. The difference between the statuses of RTS of DMUs can be obtained by the single-stage and two-stage DEA methods, definition of the input and output items for evaluating the highway maintenance are obtained as well. In the following, we provide a short review of the literature on traditional highway maintenance performance analysis, DEA highway maintenance performance evaluation, and RTS in DEA.

\section{Literature review}

\subsection{Traditional performance evaluation for highway maintenance}

The United States Highway Performance Monitoring System (HPMS) was established in 1978 with the main objective of providing information relevant to the current highway situation, performance, and operational characteristics for the Federal Government. Rao (1982) reported that the fiscal constraints on highway performance were based on monitoring three layers, i.e. highway surface condition, degree of congestion, and highway safety. Since the lack of adequate maintenance can cause safety issues as well as inconveniences in travel, the performance of highway maintenance is one of several important issues in highway performance evaluation. McMullen (1986) used questionnaires to investigate major highway maintenance engineering items, and classified these items into 6 categories of Pavement, Roadside, Traffic Service, Bridges, Drainage, and others. Various highway maintenance projects should consider the influence of the user's cost and its relationship to the highway performance, Wei and Schonfeld (1998) proposed a studying structure to emphasize that for overcoming major shortcomings of relevant studies conducted earlier. The results would thus assist policy makers in lowering the user's cost and elevating the highway maintenance efficiency. Rouse and Putterill (2000) expanded the scope of management accounting to demonstrate that the physical environment is a major omitted variable in highway performance reporting, and focus on the nature and extent of the impact of environmental cost drivers on costs of highway maintenance. The Highway Development and Management Model (HDM-4), targets the need for de- velopment of a performance evaluation system by highway management offices to establish an evaluation system that establishes the quality of highway maintenance by instituting key maintenance items and weights. Jain et al. (2005) collected cracking, raveling, potholing, and roughness data, analyzed these, and used them for calibration of the HDM-4 pavement deterioration model and for prediction of distress to develop maintenance management strategies. Khan and Odoki (2010) derived optimum pavement maintenance standards using the HDM4 model, which could be used for decision-making purposes. In practice, traditional performance evaluation methods in which each performance indicator is used in relation to one input and one output only, continue to be the method of choice in reporting performance in highway maintenance. However, the main limitation of the traditional method is that the decision on key highway maintenance items and weights is still carried out by experts, so the final results are biased by human preference, which in some cases can strongly influence the results of evaluation. In contrast to the traditional method, the recent focus has been on introducing more complex performance methods such as the DEA method. If several performance indicators are combined in some manner to gain some view of the overall performance of a DMU, that view may accord better with that gained using DEA, as both views would be based on simultaneous consideration of multiple inputs and outputs (Thanassoulis et al. 1996).

\subsection{The DEA performance evaluation of highway maintenance}

Farrel (1957) pioneered the concept based on nonparametric efficiency approach using a non-prespecified production function to replace a prespecified production function in order to find the efficiency frontier for evaluating the efficiency of a DMU. Charnes et al. (1978) developed the DEA method, which is a generalized mathematical model containing multiple inputs and outputs for evaluating performance. Cook et al. (1991) applied the DEA model to obtain efficiency measures pertaining to highway maintenance patrols by taking account of two particular environmental characteristics: percentage of privatization, and traffic level. Ramanathan (1985) pointed out that cost, quantity, quality, and their correlations are the most important factors for evaluating highway maintenance performance. Hjalmarsson and Odeck (1996) constructed efficiency measures for the utilization of trucks in road construction and maintenance using DEA model. The performance of heavy trucks, owned and operated by the Norwegian public roads administration, was measured from the point of view of technical efficiency. To examine the effects of amalgamation and policy changes on scale economies and performance of the highway management function of New Zealand's Territorial Local Authorities, Charnes et al. (1978) constant returns to scale (CRS) and Banker et al. (1996) variable returns to scale (VRS) input oriented DEA models were used by Rouse and Putterill (2005). Rouse and Chiu (2009) measured the 3Es using three separate DEA mod- 
els to evaluate road surface paving on efficiency, effectiveness and economy ${ }^{1}$. The road conditions used in their model were based on the road ratio of municipal/village as designated by regulatory agencies, and questionnaire results on paving surface damaging conditions. Their model identifies organizations that perform highly over all three dimensions. Due to the lack of investigation of RTS in each of three processes for measuring efficiency, effectiveness and economy in previous highway maintenance studies, less information regarding how the RTS of each process causes inefficiency can be obtained.

\subsection{Methods for analyzing RTS in DEA}

Banker et al. (1984) first proposed the method for analyzing RTS in DEA, which can determine the RTS classification. Estimation of RTS, which is one of the critical issues in DEA models, has been extensively studied. Traditionally, the Charnes-Cooper-Rhodes (CCR) and Banker-Charnes-Cooper (BCC) models proposed by Charnes et al. (1978) and Banker et al. (1996), respectively, can be employed to estimate the status of RTS for DMUs (Banker 1984; Banker et al. 1984; Banker, Thrall 1992; Seiford, Zhu 1999b; Zhu 2000). The aforementioned approaches had weakness in the presence of alternative optimal solutions. Golany and Yu (1997), Banker et al. (2004), Jahanshahloo and Soleimani-damaneh (2004) provided alternative methods for the estimation of RTS in DEA. The sensitivity and stability analyses of RTS classification in DEA were discussed by Seiford and Zhu (1999a) and Jahanshahloo et al. (2005). Soleimanidamaneh (2009a) proposed an algorithm with some tests which reduce the computational complexity when one uses the DEA technique to distinguish the efficiency position and the RTS classification of DMUs. Free disposal hull (FDH) models, unlike the convex DEA models, which ensures that efficiency evaluations are effected from only actually observed performance. Kerstens and Vanden Eeckaut (1999) introduced a method for this for the first time. Soleimani-damaneh et al. (2006) modified Kerstens and Vanden Eeckaut's (1999) method and proposed an equivalent simple technique for testing RTS in FDH models, which has the advantage of minimal computational requirements for their estimation. Soleimanidamaneh and Reshadi (2007) further proposed a polynomial-time algorithm to overcome those computational problems. Soleimani-damaneh and Mostafaee (2009) determined the RTS classification of FDH-efficient and FDH-inefficient units in FDH models using a ratio-based approach, and some stability intervals for radial variations in outputs while preserving the RTS classification are obtained. Those are studies about the determination of RTS in DEA models; however, weakness occurs when applying the traditional RTS analysis to the multi-stage DEA with intermediate inputs and outputs between production stages. For example, for a two-stage DEA with

\footnotetext{
13Es: "Efficiency" concerns the relationship between cost and quantity; "Effectiveness" covers the relationship between quantity and quality, whereas "Economy" refers to the relationship between cost and quality (Rouse et al. 1997).
}

intermediate inputs and outputs, traditional RTS does not provide decision-makers full information when the status of IRS was presented in both stages simultaneously.

This short review illustrates that some analytical avenues in earlier published studies were under-explored, especially with respect to inefficiency issues and a cause and effect analysis of decision-making. To our knowledge the literature lacks documentation on applications of DEA to the RTS of highway maintenance operations. Meanwhile, most current RTS research as mentioned above is conducted on the quantitative estimation aspect of DEA; however, the integrated relationship between different stages of the multi-stage RTS has not yet been discussed. In an endeavor to find robust analytical tools, the study reported here explores the use of the IRRS as an analytical tool for bridging the gap of the weakness of the literature and shows that the multi-stage DEA with IRRS yields more appropriate results than the single-stage RTS identification. The objective of this study is to establish a procedure for improving integration of the RTS between different stages.

\section{Theoretical bases}

The production function is defined as the envelopment of the maximum production for given inputs in frontier analysis. It is also referred to as the production frontier or production possibility curve (PCC) that can be used for evaluating the relevant performance among various DMUs. The method of applying the production frontier concept for performance evaluation includes Parametric Approach and Non-Parametric approaches (Førsund et al. 1980). In this research, the non-parametric approach DEA was used for investigating the returns to scale relationship of a non-prespecified production function.

\subsection{The single-stage DEA method}

The traditional DEA method applies the CCR and BCC models to obtain radial efficiencies; it uses equal ratios for adjusting the input and output for both models. When non-zero slacks occur, the efficiency value may be overestimated, and hence, the above measurements may become inappropriate. Tone (2002) developed an efficiency evaluation model that take slacks of the input and output items into account by using the non-radial slacks-based measure method to improve the traditional radial evaluation method, so that non-zero slacks can be included in the performance evaluation. In this research, the variable slack-based DEA is used in the proposed method to gauge the efficiency of each DWS.

In this paper, the non-oriented SBM DEA model proposed by Tone (2002) is used for measuring the overall operational efficiency to assist DWSs in minimizing the resource consumption, and maximizing the final outputs of maintenance simultaneously when intermediate products are fixed at current levels. The structure of nonoriented SBM model shown in Fig. 1 is represented mathematically by Eq. (1): 


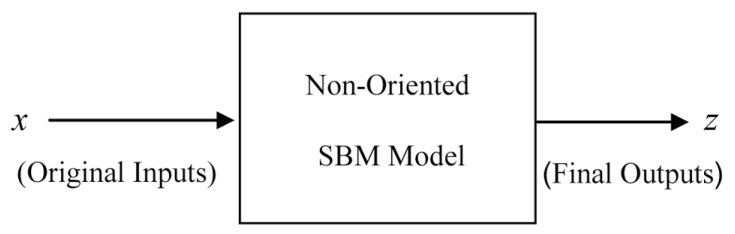

Fig. 1. Schematic diagram of traditional single-stage nonoriented SBM model

$$
\begin{array}{llc}
\operatorname{Min}_{\lambda, s^{+}, s^{-}} & \frac{1-\frac{1}{\mathrm{~N}}\left(\sum_{\mathrm{n}=1}^{N} \frac{s_{k n}^{-}}{x_{\mathrm{kn}}}\right)}{1+\frac{1}{\mathrm{P}}\left(\sum_{\mathrm{p}=1}^{P} \frac{s_{k p}^{+}}{z_{\mathrm{kp}}}\right)} \\
\text { s.t. } & \sum_{j=1}^{J} \lambda_{j} x_{j n}=x_{k n}-s_{k n}^{-} & \\
& \sum_{j=1}^{J} \lambda_{j} z_{j p}=z_{k p}+s_{k p}^{+} & p=1, \ldots, N \\
& \lambda_{j} \geq 0 \quad j=1, \ldots, J, &
\end{array}
$$

where: $s_{k n}^{-}-$the $n^{\text {th }}$ slack variable of the $\mathrm{k}^{\text {th }}$ DMU; $s_{k n}^{+}-$ the $n^{\text {th }}$ surplus variable of the $k^{\text {th }}$ DMU; $\lambda_{j}-$ the efficiency variable of the $j^{\text {th }} \mathrm{DMU} ; x_{k n}-$ the $n^{\text {th }}$ input of the $k^{\text {th }}$ DMU; $z_{k p}-$ the $p^{\text {th }}$ output of the $k^{\text {th }}$ DMU.

\subsection{The two-stage DEA method}

In the traditional single-stage DEA model, the original input and final output items are used for analyzing performance. For example, resources such as manpower, machinery, and budget are used as direct input items whereas expenditures on budget culverts, and safety are obtained directly as the final output items for analyzing the performance of various DMUs.

Because each DWS may have different scale of maintenance (e.g. highway length), errors will be introduced in the evaluation results if the scale or highway length is not considered in the evaluation. Hence, the effect of highway length that each DWS is maintaining on the final performance evaluation must be accounted for by separating the production efficiency and service efficiency into two different performance indicators to be evaluated separately. In this regard, using the traditional single-stage DEA model will be biased. Hence, the twostage DEA model is used to measure the production efficiency, service efficiency in a unified model, and the single-stage DEA model is used to measure the overall efficiency separately to identify the effects on the fixed scale of maintenance and the RTS of each process.

\subsubsection{The first stage}

The first-stage of evaluation is to investigate how to reduce the original inputs such as manpower, and machinery in order to reduce the production cost at a given length of the road maintained by each DWS, as shown in Fig. 2.

The input-oriented model proposed by Tone (2002) can be expressed mathematically as:

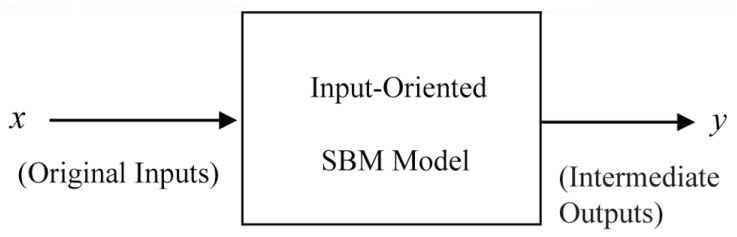

Fig. 2. Schematic diagram of the first-stage input oriented SBM model

$$
\begin{array}{ll}
\begin{array}{ll}
\text { Min } \\
\lambda, s^{-}
\end{array} & 1-\frac{1}{\mathrm{~N}}\left(\sum_{\mathrm{n}=1}^{N} \frac{s_{k n}^{-}}{x_{\mathrm{kn}}}\right) \\
\text { s.t. } & \sum_{j=1}^{J} \lambda_{j} y_{j m} \geq y_{k m} \quad m=1, \ldots, M \\
& \sum_{j=1}^{J} \lambda_{j} x_{j n}=x_{k n}-s_{k n}^{-} \quad n=1, \ldots, N \\
& \lambda_{j} \geq 0 \quad j=1, \ldots, J,
\end{array}
$$

where: $s_{k n}^{-}-$the $n^{\text {th }}$ input slack value of the $k^{\text {th }}$ DMU; $\lambda_{j}$ - the efficiency of the $j^{\text {th }} \mathrm{DMU} ; x_{k n}-$ the $n^{\text {th }}$ input of the $k^{\text {th }} \mathrm{DMU} ; y_{k m}-$ the $m^{\text {th }}$ output of the $k^{\text {th }}$ DMU.

The input-oriented efficiency is examined based on the concept that the intermediate output level is given for investigating the efficiency of the original inputs utilization.

\subsubsection{The second stage (service process): output-oriented SBM model}

Because the length of road maintained is fixed, the objective of the service process is to seek how the amount of the output of highway maintenance can be expanded based on the intermediate output of the previous production process. Hence, the output-oriented SBM mode is used to maximize the final output at the given length of road maintained, as shown in Fig. 3.

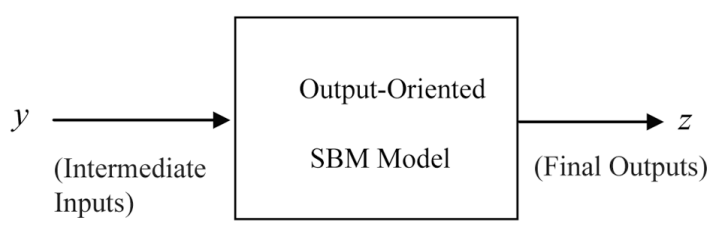

Fig. 3. Schematic diagram of the second-stage output oriented SBM model

The SBM output-oriented model is based on the equal level of intermediate output from the previous process to the final output accomplishment as much as possible for evaluating the service efficiency of various DWSs. The output-oriented SBM model proposed by Tone (2002) can be expressed by the following equation:

$$
\begin{array}{ll}
\operatorname{Min}_{\lambda, s^{+}} & \frac{1}{1+\frac{1}{\mathrm{P}}\left(\sum_{\mathrm{p}=1}^{P} \frac{s_{k p}^{+}}{\mathrm{z}_{\mathrm{kp}}}\right)} \\
& \\
\text { s.t. } & \sum_{j=1}^{J} \lambda_{j} z_{j p}=z_{k p}+s_{k p}^{+} \quad p=1, \ldots, P \\
& \sum_{j=1}^{J} \lambda_{j} y_{j m} \leq y_{k m} \quad m=1, \ldots, M \\
& \lambda_{j} \geq 0 \quad j=1, \ldots, J,
\end{array}
$$


where: $s_{k n}^{+}-$the $n^{\text {th }}$ surplus of the $k^{\text {th }}$ DMU; $\lambda_{j}-$ the efficiency of the $j^{\text {th }}$ DMU; $y_{k m}-$ the $m^{\text {th }}$ input of the $k^{\text {th }}$ DMU; $z_{k p}-$ the $p^{\text {th }}$ output of the $k^{\text {th }}$ DMU.

\subsection{The RTS (Returns to Scale) analysis}

Using the Single-stage DEA model, the RTS of a DMU can be obtained by using the CCR and BCC models. The relationships among technical efficiency ( $\left.T E_{C R S}\right)$, pure technical efficiency ( $\left.T E_{V R S}\right)$, and scale efficiency $(S E)$ can be expressed as:

$$
T E_{C R S}=T E_{V R S} \times S E .
$$

The production, service or operational technology may be characterized by Non-Decreasing Returns to Scale (NDRS) or Non-Increasing Returns to Scale (NIRS). If NDRS (NIRS) is imposed on the technology, technical efficiency $T E_{N D R S}\left(T E_{N I R S}\right)$ will be obtained.

There are three possible RTSs in the production stage, i.e. Increasing Returns to Scale (IRS), Decreasing Returns to Scale (DRS) and CRS as shown in Fig. 4. It is important to offersuggestions on resource allocation when the results of RTS evaluation are investigated. For example, if the output increases more than the input, a rational manager will be inclined to increase the input in IRS production. If a DMU experiences a DRS, the output scale must be reduced to avoid wasting the input resources, whereas the DMU that has constant returns to scale is the Most Productive Scale Size (MPSS).

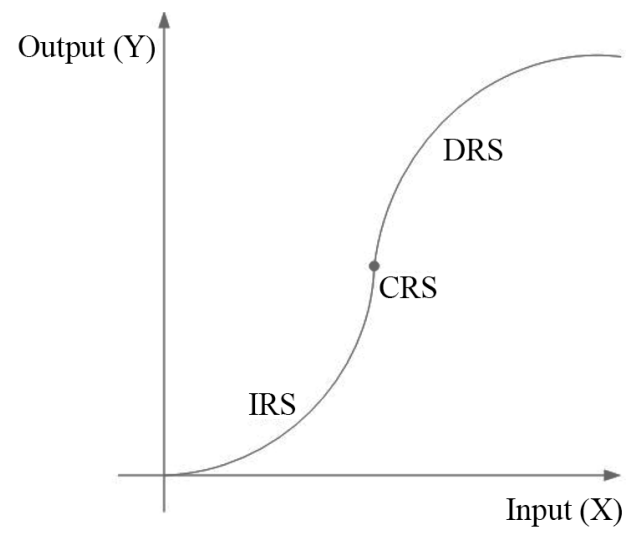

Fig. 4. Schematic diagram of returns to scale

The developments with respective to returns to scale in DEA are made precise in Färe et al. (1985), for which they give the following characterizations:

If $T E_{C R S}=T E_{V R S}$, then the production technology has the characteristic of CRS;

If $T E_{C R S}<T E_{N I R S}=T E_{V R S}$, then the production technology has the characteristic of DRS;

If $T E_{C R S}=T E_{N I R S}<T E_{V R S}$, then the production technology has the characteristic of IRS.

When the evaluation is based on the SBM DEA model, the summation of intensity variables can be used to determine the characteristic of RTS (Banker et al. 1996) shown as:

$\Sigma \lambda<1$ : RTS becomes IRS (Increasing Returns to Scale);

$\Sigma \lambda=1$ : RTS becomes CRS (Constant Returns to Scale); and Scale).

$\Sigma \lambda>1$ : RTS becomes DRS (Decreasing Returns to

\subsection{Integrated correlated RTS analyses}

For long-term production, an enterprise may adjust the scale of production to an optimal RTS, and allocate resources to adjust the enterprise scale policy by using the aforementioned method. However, for the short-term analysis of less than one year it is not easy to adjust the production scale. Especially in a two-stage production with given intermediate products flowing out of the production process into the service process, ignoring these characteristics will lead to some misleading specifications of RTS for different stages in the DWS operation. In the DEA analysis, the production function is $Y=f(X)$, in which $X$ is the input, and $Y$ is the intermediate output of production process. When $\mathrm{X}$ increases $T_{1}$ times, the intermediate output increases $T_{2}$ times, thus:

If $T_{1}>T_{2}$, then production process is DRS;

If $T_{1}=T_{2}$, then production process is CRS;

If $T_{1}<T_{2}$, then production process is IRS.

If the output of a service process $(Z)$ is expressed by $Z=f(Y)$, where $Z$ is the output of the service process. $Y$ increases $T_{2}$ times, and $Z$ increases $T_{3}$ times so that the following conditions hold:

If $T_{2}>T_{3}$, then the production process is DRS; If $T_{2}=T_{3}$, then the production process is CRS; If $T_{2}<T_{3}$, then the production process is IRS.

For example, if the production process result is IRS $\left(T_{2}>T_{1}\right)$, the service process is also IRS $\left(T_{3}>T_{2}\right)$, and the outputs of the service process will increase more times than the input used in the production process. This implies that $T_{3}>T_{1}$ for the final outputs and original inputs in the traditional single-stage DEA evaluation, so that the RTS of the overall process should be IRS. Hence, when the intermediate products are present between the production and the service process with the same original inputs and final outputs as in single-stage DEA, RTS of the first-stage DEA for the production process should coincide with RTS of the second-stage DEA for the service process. The overall process RTS can thus be easily identified based on the results of two-stage DEA. The various sorted combinations of RTS in this research are listed in Table 1.

Based on the aforementioned statements, various combinations of the first-stage and the second-stage RTS have been developed in this research. The term " $y$ ", which is defined as the output from the production process, flows into the second-stage (service process) as an input; $y_{1}$ is the amount of the production process output associated with CRS, whereas $y_{2}$ is the amount of the service process input associated with CRS as shown in 
Table 1. The relationships of RTS between the Single-stage and Two-stage DEA model

\begin{tabular}{|c|c|c|c|c|c|}
\hline Type & Combinati & is to Scale & $\begin{array}{c}\text { Production Process } \\
\qquad\left(T_{2} / T_{1}\right)\end{array}$ & $\begin{array}{l}\text { Service Process } \\
\qquad\left(T_{3} / T_{2}\right)\end{array}$ & $\begin{array}{c}\text { Operational process } \\
\qquad\left(T_{3} / T_{1}\right)\end{array}$ \\
\hline \multirow{3}{*}{ Type I } & IRS & IRS & $>1$ & $>1$ & $>1$ ( IRS ) \\
\hline & CRS & CRS & 1 & 1 & $=1(\mathrm{CRS})$ \\
\hline & DRS & DRS & $<1$ & $<1$ & $<1($ DRS $)$ \\
\hline \multirow{3}{*}{ Type II } & IRS & CRS & $>1$ & 1 & $>1$ ( IRS ) \\
\hline & IRS & DRS & $>1$ & $<1$ & Undecided \\
\hline & CRS & DRS & 1 & $<1$ & $<1 （ \mathrm{DRS})$ \\
\hline \multirow{3}{*}{ Type III } & CRS & IRS & 1 & $>1$ & $>1 \quad($ IRS $)$ \\
\hline & DRS & IRS & $<1$ & $>1$ & Undecided \\
\hline & DRS & CRS & $<1$ & 1 & $<1 （ \mathrm{DRS})$ \\
\hline
\end{tabular}

Note: "Undecided" indicates that the returns to scale of the overall process cannot be identified by the two-stage DEA model.

Type-I

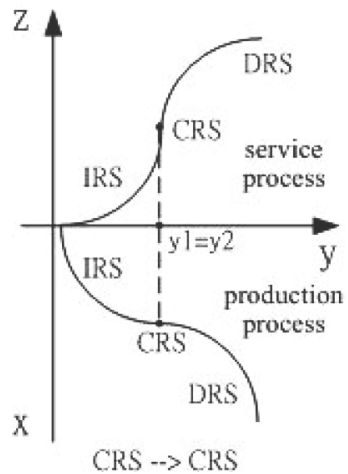

Type-II

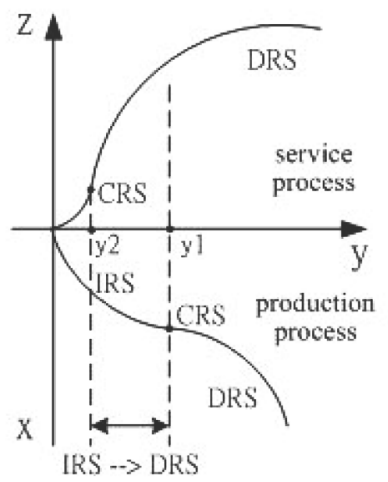

Type-III

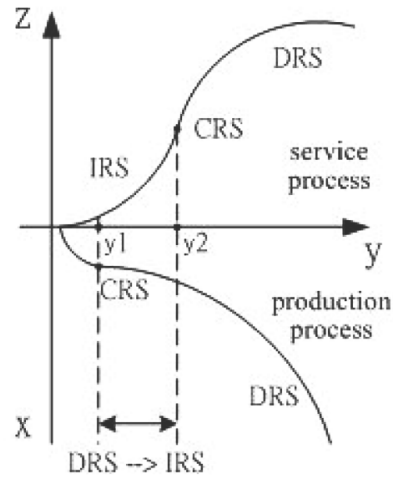

Fig. 5. Schematic diagram of the integrated returns to scale

Fig. 5 products $y_{1}$ and $y_{2}$ represent the possible ranges that are produced by the intermediate products in the production process to be used in the service process. The possible ranges of intermediate products between $y_{1}$ and $y_{2}$ can be deducted into three combinations: Type-I with $y_{1}=y_{2}$, Type-II with $y_{1}>y_{2}$ and Type-III with $y_{1}<y_{2}$ (Fig. 5).

These types can be used for identifying the status of RTS of the overall process as discussed in the following:

1. Type-I: The RTSs in both the production and the service processes:

1) If both the production and the service processes have CRS production technology, the overall process is CRS;

2) If both the production and the service processes have IRS production technology, the overall process is IRS. Expanding the scales of both original inputs and final outputs is recommended;

3) If both the production and the service processes have DRS production technology, the overall process is DRS. Reducing the scales of both original inputs and final outputs is recommended.

2. Type-II: NDRS in the production process and NIRS in the service process:
1) If the production and the service process have IRS and CRS technology, respectively, the overall process is IRS. Expansion of the original inputs scale is recommended;

2) If the production and the service process have IRS and DRS technology, respectively, the RTS of the overall process may not be concluded;

3 ) If the production and the service processes have CRS and DRS technology, respectively, the overall process is DRS. Reducing the final outputs scale is recommended.

3. Type-III: NIRS in the production process and NDRS in the service process:

1) If the production and the service processes have CRS and IRS technology, respectively, the overall process is IRS. Expanding the final outputs scale is recommended;

2) If the production and the service processes have DRS and IRS technology, respectively, the RTS of the overall process may not be concluded;

3) If the production and the service process processes have DRS and CRS technology, respectively, then the overall process is DRS. Reducing the original inputs scale is recommended. 
Table 2. Actions responsive to the relationship returns to scale

\begin{tabular}{ccccc}
\hline & & \multicolumn{3}{c}{ Service Process } \\
\cline { 3 - 4 } & & IRS & CRS & DRS \\
\hline \multirow{3}{*}{ Production Process } & IRS & Increase Scale & Increase Scale & Cannot be Determined \\
& CRS & Increase Scale & Maintain Current Scale & Decrease Scale \\
& DRS & Cannot be Determined & Decrease Scale & Decrease Scale \\
\hline
\end{tabular}

The integrated RTS relationships are discussed in the above paragraphs and listed in Table 2. Except the case in which the two stages have opposite RTS characteristics, all other RTS combinations listed in Table 2 can lead to identifying the overall process RTS clearly.

\section{Empirical results}

The 2002 highway maintenance data published by the Department of Highway Construction and Maintenance were used in the case studies to confirm the validity of the proposed procedure. The study targeted the 31 DWSs included in the report to perform performance evaluation using the proposed two-stage DEA model with the firststage input-oriented and the second-stage output-oriented SBM model for estimating the production and service efficiency scores, respectively. The resulting RTS characteristics are compared with those obtained by a nonorientation single-stage SBM model according to the proposed IRRS in order to confirm the advantages of the procedure proposed in this research.

\subsection{Selection of DMUs for conducting performance evaluation}

Selecting appropriate DMUs is the first step for conducting the evaluation. All DMUs selected for carrying out the DEA model must be homogeneous; the numbers of DMU selected for evaluation should exceed three times the total number of input and output items for discrimination purpose. Heterogeneous DMUs or inadequate selections of the input and output items will cause biased results. The number of input and output items for all DMUs must be identical with highly homogeneous production characteristics in order to generate appropriate and useful information to be referenced later by managers. All DWSs of the Department of Highway Construction and Maintenance are the fundamental highway maintenance units with similar organization and missions to maintain provincial and county highway system. All DWSs are regulated by the same agencies, and hierarchical systems with similar budgets, manpower and machinery to carry out similar tasks. Hence, these units have highly similar characteristics, and thus meet the requirements for carrying out the DEA analyses.

\subsection{Selection of the input and output items}

When adopting the DEA method to evaluate performance of DMUs, we must consider the organizational target, accuracy of the data acquired, relationship between the input and output items, number of input and output items and sufficient number of DMUs for determining DMUs' efficiency. The "Regulations on Highway Construction and Maintenance" requires that the highway maintenance cover road foundations, bank slopes, surfaces, bridges, tunnels, drainage, safety facilities, and scenery, whereas the scope of maintenance includes surface facilities and equipment, subsurface underground pipelines to repair damages, digging and filling, and right-of-way.

The input items for road maintenance include manpower, machinery and budget; identifying these items is usually non-controversial. However, the determination of output items may be disputable. Using the road surface maintenance as an example, the traditional evaluation emphasizes the evaluation of surface indices such as road surface roughness, skid resistance, and strength of the road construction. Because the scope of road maintenance is too wide to be practically implemented, a detailed continual quantitative survey of the damage extent is not easy to carry out. In actuality, the results of scheduled investigations are usually taken as the measure of overall road quality. This is done by targeting primary roads for scheduled annual inspection on roughness, skid resistance, and deflection; the results are considered representative of road surface quality. The information collected through visual inspection, or reported by the general public is used for arranging scheduled or non-scheduled maintenance operations. Actual comprehensive surveys of damages are for practical reasons not carried out, so the information collected does not reflect the real road quality. Therefore, in this research, the highway maintenance funds are used to replace the traditional scheduled sampling inspection for reflecting the real road condition.

Using the road surface maintenance as an example, if the surface area of asphalt pavement is proportional to the damaged area, the road surface maintenance funds available to the various sections may have discrepancies due to differences in the unit cost specified in the contract. In this research, the information included in the 308 official road maintenance and repairing contracts for the period from 2002 and 2004 as collected from the Maintenance and Construction Office (MCO) were examined. The ANOVA test is further used for testing whether various MCOs have significant difference in their road repairing project contracts. As shown in Table 3, the results indicate that the null hypothesis of no difference can be accepted, and that the unit price specified in open contracts does not have an obvious difference. Hence, expenditures of the road maintenance represent actually how much maintenance operation has been conducted; they also indicate the degree of road quality. Therefore, the actual road maintenance expenditures based on the data provided by the 5 MCOs were used in this research to replace the traditional scheduled data collection by sampling road damages for evaluating the output. 
Table 3. ANOVA tests for maintenance and construction offices' road repairing project contracts, unit: NT\$/Tone/ Asphalt

\begin{tabular}{lccccc}
\hline & $\mathrm{A}$ & $\mathrm{B}$ & $\mathrm{C}$ & $\mathrm{D}$ & $\mathrm{E}$ \\
\hline Maximum & 5,625 & 5,025 & 4,959 & 5,687 & 5,846 \\
Minimum & 2,006 & 2,005 & 2,050 & 2,000 & 2,663 \\
Average & 3,300 & 3,099 & 3,553 & 3,280 & 3,057 \\
Standard Deviation & 804 & 729 & 811 & 872 & 892 \\
\hline
\end{tabular}

ANOVA tests: $P$ value $=0.07$

\subsubsection{Input items}

Most research includes manpower, machinery, and budget as the regular highway maintenance input items. Further evaluation of these three items indicates that except for manpower and machinery are independent, the budget that includes salary, expenditures for road maintenance and machinery repair and maintenance has double counted some of the input items. Hence, the budget item is not included in the input item for this research. Instead, numbers of employees and machinery are used.

\subsubsection{Intermediate input and output items}

In the production process, the objective of DWS is to minimize the consumption of original input resources (e.g. manpower and machinery) for maintaining a given mileage of road; in the service process, the objective of DWS is to maximize the final outputs for maintaining a fixed mileage of road. Thus, the maintenance mileage is used as an intermediate product and as an output in the production process and input in the service process, which include the total length of provincial roads and county roads maintained.

\subsubsection{Output items}

The tedious highway maintenance operations cannot be easily quantified. Hence, the highway maintenance operations are classified into 3 categories, and progress of their implementation is represented by the actual expenditures. These 3 categories include:

1) Expenditures for maintaining bridges, culverts and highway scenery: the expenditures include repairing and strengthening bridges, and cleaning and repairing culverts and roadside ditches. Because bridges and culverts vary significantly, the expenditures of maintenance are represented by the typical output items;

2) Safety and protection expenditures: the expenditures cover road surface maintenance, roadside slope protection, repairing guard rails, protecting foundations, installing signals and signs, and painting guiding lines;

3) Funds collected for commissioned road digging and repairing: road repair is different for various road surfaces, and utility companies do not have the expertise to repair roads. Hence, they usually commission the road maintenance office by paying fees to do the digging and repairing for installing pipelines. The fees collected can be used to index the degree of damages caused by other companies to the road system.

In the DEA context, problems related to discrimination between efficient and inefficient DMUs often arise if there are a relatively large number of inputs and outputs with respect to observations. Thus, the DEA model cannot accommodate too many input and output items, to avoid the situation in which the efficiencies evaluated for all DMUs are "1". The minimum number of DMU observations should be greater than three times the number of inputs plus outputs (Raab, Lichty 2002); or the minimum number of observations is equal to or greater than the product of the number of outputs and inputs (Boussofiane et al. 1991). The input and output items used in this research include: model:

1. The traditional single-stage non-oriented SBM

1) Input items: Number of employees and number of machinery;

2) Output items: expenditures for maintaining bridges, culverts and road scenery, safety and protection (including re-surfacing), and fees collected for the commissioned road surface digging for installing utility lines and repairing.

2. The two-stage DEA Model:

1) The first-stage input-oriented SBM production model:

A. Input items: number of employees and number of machinery;

B. Intermediate output items: mileage maintained.

Table 4. Descriptive statistics of inputs and outputs

\begin{tabular}{|c|c|c|c|c|}
\hline & Mean & Max. & Min. & St. Dev. \\
\hline \multicolumn{5}{|l|}{ Initial inputs } \\
\hline Number of employees (persons) & 55.6 & 107 & 22 & 15.2 \\
\hline number of machinery (vehicles) & 15.4 & 24 & 5 & 4.8 \\
\hline \multicolumn{5}{|l|}{ Intermediate product } \\
\hline mileage maintained $(\mathrm{kms})$ & 247.6 & 471.9 & 78.1 & 105.0 \\
\hline \multicolumn{5}{|l|}{ Final outputs } \\
\hline Bridges and Road Scenery (NT\$) & $9,191.2$ & 4,2217 & 978.4 & $10,406.0$ \\
\hline Protection and Safety (NT\$) & $7,272.8$ & 3,3663 & 314 & $6,847.3$ \\
\hline Road Surface Digging and Repairing (NT\$) & $7,202.2$ & 2,6707 & 313 & $5,639.5$ \\
\hline
\end{tabular}

Note: NT\$: Net Taiwan dollars. 
2) The second-stage output-oriented SBM service model:

A. Intermediate input item: mileage maintained;

B. Output items: expenditures for maintaining and repairing bridges, culverts, road scenery, safety and protection facilities and installations (including road re-surfacing), and fees collected for the commissioned road surface digging and repairing.

\subsection{Data inspection}

The total number of input and output items for the various stages are 5, 3 and 4, whereas the number of DMUs is 31 , which exceeds three times the total number of all input and output items and is greater than the product of the numbers of outputs and inputs for all stages. Hence, the evaluation results obtained using the DEA method should have sufficient discrimination power for the intended evaluation work.

\section{Results of case studies}

\subsection{Returns to scale}

The input and output items defined in the above sections are used for conducting the DEA analysis. The traditional single-stage DEA evaluation using the non-oriented SBM model is used for examining the status of RTS of the overall process, whereas the two-stage evaluation using inputoriented and out-oriented SBM models is applied for evaluating the status of RTS for each stage. Meanwhile, the IRRS (integrated relationship of returns to scale) is implemented to suggest recommendations on improving the RTS characteristics for the 31 DWSs evaluated. The relevant information and results are listed in Table 5.

Table 5. Returns to scale of the single- and two-stage DEA models

\begin{tabular}{|c|c|c|c|c|c|c|c|c|}
\hline \multirow{3}{*}{$\begin{array}{l}0 \\
\stackrel{\Sigma}{\Sigma}\end{array}$} & \multirow{3}{*}{$\stackrel{n}{3}$} & \multicolumn{5}{|c|}{ Two-stage DEA Model } & \multirow{2}{*}{\multicolumn{2}{|c|}{ Operational process }} \\
\hline & & \multicolumn{2}{|c|}{ Production Process } & \multicolumn{2}{|c|}{ Service Process } & \multirow{2}{*}{ Combination of RTS } & & \\
\hline & & $\Sigma \lambda$ & RTS & $\Sigma \lambda$ & RTS & & $\Sigma \lambda$ & RTS \\
\hline \multirow{5}{*}{ A } & D1 & 0.82 & IRS & 1.17 & DRS & —* & 1 & CRS \\
\hline & $\mathrm{D} 2$ & 0.64 & IRS & 1 & CRS & IRS** & 1 & $\mathrm{CRS}^{* *}$ \\
\hline & D3 & 0.78 & IRS & 2.96 & DRS & —* & 0.8 & IRS \\
\hline & D4 & 0.6 & IRS & 3.1 & DRS & —* & 0.72 & IRS \\
\hline & D5 & 0.43 & IRS & 1 & CRS & IRS** & 1 & $\mathrm{CRS}^{* *}$ \\
\hline \multirow{7}{*}{ B } & D6 & 1 & CRS & 2.59 & DRS & $\mathrm{DRS}^{* *}$ & 0.65 & IRS** \\
\hline & D7 & 0.77 & IRS & 2.59 & DRS & —* & 1.01 & DRS \\
\hline & D8 & 1.08 & DRS & 2.47 & DRS & DRS & 1.02 & DRS \\
\hline & D9 & 0.83 & IRS & 1.85 & DRS & —* & 1.11 & DRS \\
\hline & D10 & 0.43 & IRS & 1 & CRS & IRS & 0.95 & IRS \\
\hline & D11 & 0.55 & IRS & 1.27 & DRS & —* & 0.97 & IRS \\
\hline & D12 & 0.32 & IRS & 0.49 & IRS & IRS & 0.97 & IRS \\
\hline \multirow{7}{*}{$\mathrm{C}$} & D13 & 0.76 & IRS & 1 & CRS & IRS & 1.08 & IRS \\
\hline & D14 & 0.94 & IRS & 1.26 & DRS & —* & 1 & CRS \\
\hline & D15 & 0.64 & IRS & 0.86 & IRS & IRS & 0.8 & IRS \\
\hline & D16 & 0.58 & IRS & 0.77 & IRS & IRS & 0.97 & IRS \\
\hline & D17 & 0.36 & IRS & 0.84 & IRS & IRS & 0.81 & IRS \\
\hline & D18 & 0.19 & IRS & 1 & CRS & IRS & 0.27 & IRS \\
\hline & D19 & 0.51 & IRS & 1.76 & DRS & —* & 0.75 & IRS \\
\hline \multirow{6}{*}{$\mathrm{D}$} & D20 & 0.34 & IRS & 0.68 & IRS & IRS & 0.59 & IRS \\
\hline & D21 & 0.36 & IRS & 0.57 & IRS & IRS & 0.77 & IRS \\
\hline & D22 & 0.65 & IRS & 1.51 & DRS & —* & 0.53 & IRS \\
\hline & D23 & 0.21 & IRS & 0.33 & IRS & IRS & 0.44 & IRS \\
\hline & D24 & 0.26 & IRS & 0.6 & IRS & IRS & 0.44 & IRS \\
\hline & D25 & 0.37 & IRS & 0.85 & IRS & IRS & 0.24 & IRS \\
\hline \multirow{6}{*}{$\mathrm{E}$} & D26 & 1 & CRS & 2.31 & DRS & DRS** & 0.38 & IRS** \\
\hline & D27 & 27 & DRS & 2.72 & DRS & DRS** & 0.58 & IRS** \\
\hline & D28 & 0.64 & IRS & 1.49 & DRS & —* & 0.36 & IRS \\
\hline & D29 & 0.56 & IRS & 1.3 & DRS & —* & 0.23 & IRS \\
\hline & D30 & 0.51 & IRS & 2.62 & DRS & —* & 0.57 & IRS \\
\hline & D31 & 0.67 & IRS & 1.06 & DRS & —* & 0.26 & IRS \\
\hline \multicolumn{9}{|l|}{ Note: } \\
\hline
\end{tabular}


As shown in Table 5 and based on the characteristics defined in this research, the combinations of the characteristics of returns to scale (production process $\rightarrow$ service process) obtained by the two-stage analysis for the 31 DWSs are IRS $\rightarrow$ IRS, IRS $\rightarrow$ CRS, IRS $\rightarrow$ DRS, $\mathrm{CRS} \rightarrow \mathrm{DRS}$, and DRS $\rightarrow$ DRS, which are Type-III. In this case, there are no Type-I and Type-II combinations.

Comparisons of the relationship of process RTS obtained using the two-stage DEA model and the traditional single-stage DEA model are shown in Table 6. The results show that 27 of the DWSs evaluated have IRS characters in the production process, whereas in the service process, 5 DWSs have CRS character, 13 DWSs have DRS characters, and no DWS has IRS characters. For another 13 DWS, the production and the service stages have opposite RTS characters. As mentioned in the aforementioned sections, if these two stages have the opposite status of RTS, e.g. the production process is IRS and the service process is DRS, the RTS characters of overall process cannot be determined based on the resulting integrated RTS relationship. The other 14 DWSs have the IRS->IRS and IRS->CRS combinations, thus, the status of RTS of the overall process should be IRS. The results obtained using the traditional single-stage DEA model suggest that 2 DWSs (D2 and D5) operate under the status of CRS, which is different from the results obtained using the method proposed in this research. Additionally, while 27 DWSs have IRS status in their production process as mentioned above, the other 4 DWSs have CRS and/or DRS status in their production and service processes. Hence, 3 DWSs (D6, D26 and D27) have different RTS status obtained by the proposed IRRS from those obtained using the traditional single-stage DEA model. The results again indicate that the identification of the status of RTS of DMUs is different between the twostage and single-stage DEA models.

As shown by the results listed in Table 6, except for the 13 DWSs that have the indeterminate IRS $\rightarrow$ DRS pattern, all other 14 DWSs, which have IRS $\rightarrow$ IRS or IRS $\rightarrow$ CRS combinations in their production and service process, are characterized by IRS using IRRS; the remaining 4 DWSs are characterized by DRS. Furthermore, results show larger discrepancies in RTS obtained from the second-stage output-oriented DEA, where 9 DWSs character by IRS, 5 DWSs character by CRS; and 13 DWSs character by DRS. However, 27 DWSs are identified as IRS in their production process, which is more than $80 \%$ of the overall DWSs. The results reveal that current district scales of 14 DWSs, which have IRS $\rightarrow$ IRS or IRS $\rightarrow$ CRS combinations in their production and service process, are too small; increasing their input scale is recommended. Because each DWS is maintaining a fixed length of road, reallocating available DHC resources is also recommended. Additionally, some DWSs with IRS in their production process may be merged to increase the scale for improving the performance. However, other factors such as geographic locations need to be considered to improve the scale efficiency. For example, only geologically adjacent DWSs can be merged. Using Office D as an example, Districts D20, D22, D23, D24, and D35 may be selected as the targeted District combination.

\subsection{Results of performance evaluation}

Results of the relative efficiency for the whole DWSs in each section district including production efficiency, service efficiency, and the overall efficiency are listed in Table 6 . The objective function used to evaluate the overall efficiency in the traditional single-stage non-oriented SBM model is to minimize the initial inputs and maximize the final output simultaneously. However, when the two-stage model is used to evaluate performance of DWSs at a given level of intermediate products between production and service processes, the objective of the first-stage inputoriented SBM model is to seek the reduction of inputs at its given intermediate outputs, whereas the objective of the second-stage output-oriented SBM DEA model is to seek the increase of the final outputs at the given intermediate inputs flow from the production process. As mentioned in the aforementioned sections, measurement of the DWSs' performance using the two-stage DEA model is more reasonable, due to the existence of fixed intermediate products between the production and service processes. The following sections present the performance evaluation using the two-stage DEA model.

Table 6. RTS Comparisons of the two-stage and single-stage DEA

\begin{tabular}{|c|c|c|c|c|c|c|c|}
\hline \multicolumn{5}{|c|}{ Two-stage DEA model } & \multirow{2}{*}{\multicolumn{2}{|c|}{$\begin{array}{c}\text { Single-stage } \\
\text { DEA model } \\
\text { (Operational process) }\end{array}$}} & \multirow{3}{*}{$\begin{array}{l}\text { Consistency } \\
\# \text { of DWSs } \\
\end{array}$} \\
\hline \multicolumn{2}{|c|}{ Production process } & \multicolumn{2}{|c|}{ Service process } & \multirow{2}{*}{$\begin{array}{c}\begin{array}{c}\text { Integrate returns } \\
\text { to scale results }\end{array} \\
\text { RTS } \\
\end{array}$} & & & \\
\hline RTS & \# of DWSs & RTS & \# of DWSs & & RTS & \# of DWSs & \\
\hline \multirow{5}{*}{ IRS } & \multirow{5}{*}{27} & IRS & 9 & IRS & IRS & 9 & 9 \\
\hline & & CRS & 5 & IRS & $\begin{array}{l}\text { IRS } \\
\text { CRS }\end{array}$ & $\begin{array}{c}3 \\
2 * *\end{array}$ & 3 \\
\hline & & \multirow{3}{*}{ DRS } & \multirow{3}{*}{13} & \multirow{3}{*}{-* } & IRS & 9 & \multirow{3}{*}{$-*$} \\
\hline & & & & & CRS & 2 & \\
\hline & & & & & DRS & 2 & \\
\hline CRS & 2 & DRS & 2 & DRS & IRS & $2 * *$ & 0 \\
\hline \multirow{2}{*}{ DRS } & \multirow{2}{*}{2} & \multirow{2}{*}{ DRS } & \multirow{2}{*}{2} & \multirow{2}{*}{ DRS } & IRS & $1 * *$ & \multirow{2}{*}{1} \\
\hline & & & & & DRS & 1 & \\
\hline Total & 31 & \multicolumn{2}{|c|}{31} & & \multicolumn{2}{|c|}{31} & 13 \\
\hline
\end{tabular}


Table 7. Efficiencies of production, service and operational processes and their rankings

\begin{tabular}{|c|c|c|c|c|c|c|c|c|c|c|}
\hline \multirow[b]{3}{*}{ MCO } & \multirow[b]{3}{*}{ DWS } & \multicolumn{6}{|c|}{ Two-stage DEA } & \multirow{2}{*}{\multicolumn{3}{|c|}{$\begin{array}{l}\text { Single-stage DEA } \\
\text { Operational process }\end{array}$}} \\
\hline & & \multicolumn{3}{|c|}{ Production process } & \multicolumn{3}{|c|}{ Service process } & & & \\
\hline & & Efficiency & Average & Rank & Efficiency & Average & Rank & Efficiency & Average & Rank \\
\hline \multirow{5}{*}{ A } & D1 & 0.558 & & 5 & 0.568 & \multirow{5}{*}{0.634} & 12 & 1.000 & & 1 \\
\hline & D2 & 0.430 & & 16 & 1.000 & & 1 & 1.000 & & 1 \\
\hline & D3 & 0.542 & 0.455 & 6 & 0.228 & & 16 & 0.289 & 0.726 & 15 \\
\hline & D4 & 0.466 & & 10 & 0.376 & & 14 & 0.342 & & 14 \\
\hline & D5 & 0.277 & & 29 & 1.000 & & 1 & 1.000 & & 1 \\
\hline \multirow{7}{*}{ B } & D6 & 1.000 & \multirow{7}{*}{0.451} & 1 & 0.058 & \multirow{7}{*}{0.301} & 29 & 0.165 & & 19 \\
\hline & D7 & 0.447 & & 12 & 0.129 & & 24 & 0.119 & & 26 \\
\hline & D8 & 0.454 & & 11 & 0.073 & & 27 & 0.154 & & 20 \\
\hline & D9 & 0.443 & & 14 & 0.083 & & 25 & 0.088 & 0.173 & 29 \\
\hline & D10 & 0.287 & & 27 & 1.000 & & 1 & 0.445 & & 10 \\
\hline & D11 & 0.334 & & 23 & 0.135 & & 23 & 0.136 & & 24 \\
\hline & D12 & 0.190 & & 31 & 0.630 & & 11 & 0.105 & & 28 \\
\hline \multirow{7}{*}{$\mathrm{C}$} & D13 & 0.435 & \multirow{7}{*}{0.403} & 15 & 1.000 & \multirow{7}{*}{0.816} & 1 & 0.864 & \multirow{7}{*}{0.683} & 5 \\
\hline & D14 & 0.575 & & 4 & 0.783 & & 9 & 1.000 & & 1 \\
\hline & D15 & 0.411 & & 18 & 0.809 & & 8 & 0.739 & & 8 \\
\hline & D16 & 0.323 & & 24 & 0.419 & & 13 & 0.262 & & 16 \\
\hline & D17 & 0.282 & & 28 & 0.825 & & 7 & 0.403 & & 12 \\
\hline & D18 & 0.375 & & 20 & 1.000 & & 1 & 0.747 & & 7 \\
\hline & D19 & 0.423 & & 17 & 0.878 & & 6 & 0.766 & & 6 \\
\hline \multirow{6}{*}{$\mathrm{D}$} & D20 & 0.359 & \multirow{6}{*}{0.359} & 21 & 0.049 & \multirow{6}{*}{0.291} & 30 & 0.057 & \multirow{6}{*}{0.247} & 30 \\
\hline & D21 & 0.314 & & 26 & 0.194 & & 18 & 0.137 & & 23 \\
\hline & D22 & 0.528 & & 7 & 0.289 & & 15 & 0.441 & & 11 \\
\hline & D23 & 0.235 & & 30 & 0.632 & & 10 & 0.353 & & 13 \\
\hline & D24 & 0.316 & & 25 & 0.226 & & 17 & 0.147 & & 21 \\
\hline & D25 & 0.445 & & 13 & 0.157 & & 21 & 0.206 & & 18 \\
\hline \multirow{6}{*}{$\mathrm{E}$} & D26 & 1.000 & \multirow{6}{*}{0.605} & 1 & 0.165 & \multirow{6}{*}{0.142} & 19 & 0.648 & \multirow{6}{*}{0.256} & 9 \\
\hline & D27 & 0.982 & & 3 & 0.065 & & 28 & 0.259 & & 17 \\
\hline & D28 & 0.493 & & 8 & 0.078 & & 26 & 0.140 & & 22 \\
\hline & D29 & 0.396 & & 19 & 0.159 & & 20 & 0.134 & & 25 \\
\hline & D30 & 0.340 & & 22 & 0.153 & & 22 & 0.106 & & 27 \\
\hline & D31 & 0.490 & & 9 & 0.026 & & 31 & 0.034 & & 31 \\
\hline
\end{tabular}

As shown in Table 7, D6 and D26 have the best production efficiency, whereas D2, D5, D10, D13, and D18 have the best service efficiency. For the DWSs that have poor production efficiency, reduction of input quantities is recommended, while for DWSs with poor service efficiency, increasing output quantities is recommended. For example, D1 has the same performance value of 0.56 for both production and service process; it is recommended that the initial inputs be reduced and the final outputs increased in order to raise the overall efficiency. For D2, which has 0.43 for production efficiency and 1 for service efficiency, under the condition of maintaining a fixed length of road, the poor production efficiency can be improved by reducing the initial inputs.

For the Office of Highway Construction and Maintenance, Office $\mathrm{C}$ has the best average performance for the production process but the worst performance for the service process. The most important step is to increase the outputs of the service process, which will raise the overall efficiency. Office $\mathrm{C}$ has the best service efficiency and relatively poor production efficiency. Hence, reducing the initial inputs will improve its production efficiency.
Whether the production efficiency is significantly different from the service efficiency among DWSs in a given office or among offices needs further investigation:

1. Results of the ranking of the DWSs, which are shown in Table 8, are examined using the Wilcoxon Sign-Rank Test. All DWSs in the three different stages show no difference in their rankings. This implies that there is no significant difference among production efficiency, service efficiency and overall efficiencies;

2. Further tests are carried out for the District Engineering Offices of various Section Works Districts. Because the DWSs may belong to various District Offices, they are categorized as independent samples. Hence, the Kruskal Wallis test is used to test whether the performance of the 5 District Offices for the various stages are different. The results, which are listed in Table 9, indicate that there is no difference among the 5 District Offices for the production process. However, their performance is significantly different in the service process, and also in the overall process; 
Table 8. The Wilcoxon sign-rank test

\begin{tabular}{|c|c|c|c|c|}
\hline & & \multicolumn{2}{|c|}{ Two-Stage DEA } & \multirow{2}{*}{$\begin{array}{c}\text { One-Stage DEA } \\
\text { (Operational Efficiency) }\end{array}$} \\
\hline & & Production Efficiency & Service Efficiency & \\
\hline \multirow{2}{*}{ Two-Stage DEA } & Production Efficiency & - & 0.906 & 0.433 \\
\hline & Service Efficiency & 0.906 & - & 0.524 \\
\hline \multicolumn{2}{|c|}{ One-Stage DEA (Operational Efficiency) } & 0.433 & 0.524 & - \\
\hline
\end{tabular}

Table 9. The Kruskal Wallis test

\begin{tabular}{c|c|c}
\hline \multicolumn{2}{c|}{ Performance Index } & P-value \\
\hline \multirow{2}{*}{ Two-Stage DEA } & Production Efficiency & 0.338 \\
\cline { 2 - 3 } & Service Efficiency & 0.002 \\
\hline \multicolumn{2}{|c|}{ Operational Efficiency } & 0.002 \\
\hline
\end{tabular}

Note: Two-Tailed Test Significance Level $=10 \%$; $\mathrm{P}$ value $=0.05$ or less indicates significant difference

3. The Mann-Whitney U statistical test is used for testing whether the service efficiency differs between any pair of District Offices and whether overall efficiency differs between any pair of District Offices. The results are listed in Table 10. Using District Offices A and B as an example, their service efficiency does not appear to be significantly different, but the overall efficiency does. Hence, office A has a better average overall efficiency than Office B. The overall efficiency comparison for Offices $\mathrm{A}$ and $\mathrm{C}$ also indicates that there is no significant difference; however, Office A has a better production efficiency of $13 \%$ than Office $C$, whereas Office A has a poorer service efficiency of $28.7 \%$ than Office C. When the overall efficiency is examined, Office $\mathrm{A}$ is $6 \%$ superior to Office $\mathrm{C}$. Hence, for Office $\mathrm{A}$ and $\mathrm{C}$, the production process influences the overall efficiency more than the service process does;

Table 10. The Mann-Whitney test of the various processes for district offices $\mathrm{A}$ and $\mathrm{B}, \mathrm{A}$ and $\mathrm{C}$

\begin{tabular}{ccc}
\hline MCO & $\mathrm{H}_{0}: \mathrm{A}=\mathrm{B}$ & $\mathrm{H}_{0}: \mathrm{A}=\mathrm{C}$ \\
\hline Service process & 0.086 & 0.457 \\
Overall process & 0.011 & 0.508 \\
\hline
\end{tabular}

Note: 1. Comparisons of the performance of only A vs. B and $A$ vs. C are presented because of limitation on paper length;

2. Two-Tailed Test Significance Level $=10 \%$; $\mathrm{P}$ value $=0.05$ or less indicates significant difference

4. The Wilcoxon Sign-Rank test is further used for testing whether various Engineering District Offices have significant difference in their production efficiency and service efficiency. As shown in Table 11, the results indicate that the null hypothesis of no difference should be rejected. It reveals that Office $\mathrm{C}$ and Office $\mathrm{E}$ have significant differences in their production efficiency and service efficiency:
1) For Office $C$, there is significant difference in its production efficiency and service efficiency with obvious poor production efficiency. Reducing the initial inputs at a given intermediate output in the production process is urgently needed to raise performance. After the production efficiency is improved, the service efficiency needs to be subsequently reviewed;

2) For Office E, the performance for both processes also has a significant difference, and the service efficiency is relatively poor. Hence, the emphasis is to increase the final outputs at the given length of road to be maintained, in order to raise its service efficiency. After the service efficiency is improved, the production efficiency is then reviewed;

3) For Offices A, B, and D, there is no significant performance difference between production and service processes. Hence, both production and service processes should be improved in order to raise the performance; the improvement covers both reducing the initial inputs and increasing the final outputs.

Table 11. The Difference in Production Efficiency and Service Efficiency for the Various MCO

\begin{tabular}{ccc}
\hline MCO & Mean core & P value \\
\hline $\mathrm{A}$ & $(0.455,0.634)$ & 0.500 \\
$\mathrm{~B}$ & $(0.451,0.301)$ & 0.612 \\
$\mathrm{C}$ & $(0.403,0.816)$ & 0.018 \\
$\mathrm{D}$ & $(0.359,0.291)$ & 0.345 \\
$\mathrm{E}$ & $(0.605,0.142)$ & 0.028 \\
\hline Note: 1. & Two-Tailed Test Significance Level = 10\%; \\
\multicolumn{3}{l}{ P-value $=0.05$ or less indicates significant differ- } \\
\end{tabular}

\section{Conclusions}

This paper proposed a new procedure for identifying the status of the RTS when the intermediate products are in the presence of the overall process. Due to the fixed intermediate products between the production and service processes, the performance of the DMUs can be more appropriately evaluated using the two-stage DEA method along with IRRS. Hence, the status of RTS in each process estimated by the two-stage DEA associated with IRRS is deemed to be more reasonable and accurate. 
The length of road to be maintained is the output, and manpower and machinery are used as the input items in the production process, which leads to evaluating the performance of resource utilization. In the service process, the length of road maintained is used as the input for evaluating the road maintenance service. Additionally, the traditional road quality information was obtained by sampling to understand road surface damages; the results do not reflect the actual degree of road surface damages. In this research, the unit cost of road repairing is found to be similar for the various districts. Hence, the actual expenditures for repairing the road can realistically reflect the degree of road damages, and has been used as final outputs in this research.

The two-stage DEA model is used for evaluating the road maintenance performance of the Directorate General of Highway Construction and Maintenance. The results lead to various RTSs in each process that can be classified into three categories. Comparing the results obtained by the traditional single-stage DEA method, it is found that when the intermediate products appeared between production and service process, the two-stage DEA model is superior to the single-stage DEA model for measuring efficiencies and identifying RTSs.

In the two-stage DEA analysis, more than $80 \%$ of the DWSs (27DWSs) character with IRS. For these DWSs, increasing the input scale will raise the performance. Because the overall length of road to be maintained remains unchanged, the recommendation is to consider relocating and combining some adjacent districts for raising the scale benefit.

For all DWSs subject to the two-stage DEA, District $\mathrm{C}$ and District $\mathrm{E}$ have significantly different performance in production efficiency and service efficiency. District $\mathrm{C}$ has poor production efficiency; reducing the initial inputs at a given length of road to be maintained will raise its production efficiency. For District E, the service efficiency is worse than production efficiency. Hence, raising the final outputs while keeping the total length of road unchanged will improve the service efficiency. The production efficiency and service efficiency for Office A, Office $B$ and Office $D$ show insignificant differences, so the way to improve the performance is to reduce original inputs and increase the final outputs.

Damage to road by traffic is an important factor but is not included in this study because the area covered by the Directorate General of Highway Construction and Maintenance is so big that a large-scale survey of the complete traffic situation has not been done. Currently, only spot checking of traffic will not provide information of the actual traffic situation. Installing vehicular detectors for collecting traffic information coupled with environmental factors is recommended to collect information for future evaluation of the overall performance.

Some road maintenance input items may have the "common input" characteristics and intermediate products so that the information can be used by either the production or the service processes. Hence, using the Multiple Activities Network DEA (MNDEA) model is recommended for future evaluation of road maintenance performance. Additionally, some input items are expressed in integers; the method that is based on integer math programming is recommended for conducting the MNDEA.

The problem of indeterminate returns to scale for DWSs, which have the production IRS and the service DRS, or the production DRS and the service IRS, need to be resolved in future studies. The results of the paper can also be extended to the non-convex case using the RTS estimation techniques in FDH models. Additionally, there is a growing body of studies offering empirical evidence on distinguishing the dynamically efficient paths (e.g., Jahanshaloo et al. 2006), and the computational complexity point of view (e.g., Soleimani-damaneh 2009b). The computational complexity point of the two-stage framework can be incorporated in by introducing dynamic DEA in the determination of the status of returns to scale.

\section{Acknowledgement}

The authors would like to thank three anonymous reviewers for their constructive comments which are very helpful in improving the paper.

\section{References}

Banker, R. D.; Thrall, R. M. 1992. Estimation of returns to scale using data envelopment analysis, European Journal of Operational Research 62(1): 74-84. http://dx.doi.org/10.1016/0377-2217(92)90178-C

Banker, R. D. 1984. Estimating most productive scale size using data envelopment analysis, European Journal of Operational Research 17(1): 35-44. http://dx.doi.org/10.1016/0377-2217(84)90006-7

Banker, R. D.; Chang, H.; Cooper, W. W. 1996. Equivalence and implementation of alternative methods for determining returns to scale in data envelopment analysis, European Journal of Operational Research 89(3): 473-481. http://dx.doi.org/10.1016/0377-2217(95)00044-5

Banker, R. D.; Cooper, W. W.; Seiford, L. M.; Thrall, R. M.; Zhu, J. 2004. Returns to scale in different DEA models, European Journal of Operational Research 154(2): 345362. http://dx.doi.org/10.1016/S0377-2217(03)00174-7

Banker, R. D.; Charnes, A.; Cooper, W.W. 1984. Some models for estimating technical and scale inefficiencies in data envelopment analysis, Management Science 30(9): 10781092. http://dx.doi.org/10.1287/mnsc.30.9.1078

Boussofiane, A.; Dyson, R. G.; Thanassoulis, E. 1991. Applied data envelopment analysis, European Journal of Operational Research 52(1): 1-15. http://dx.doi.org/10.1016/0377-2217(91)90331-O

Charnes, A.; Cooper, W. W.; Rhodes, E. 1978. Measuring the efficiency of decision making units, European Journal of Operational Research 2(6): 429-444. http://dx.doi.org/10.1016/0377-2217(78)90138- $\underline{8}$

Cook, W. D.; Zhu, J. 2007. Classifying inputs and outputs in data envelopment analysis, European Journal of Operational Research 180(2): 692-699.

http://dx.doi.org/10.1016/j.ejor.2006.03.048

Cook, W. D.; Kazakov, A.; Roll, Y.; Seiford, L. M. 1991. A data envelopment approach to measuring efficiency: Case analysis of highway maintenance patrols, The Journal of Socio-Economics 20(1): 83-103.

http://dx.doi.org/10.1016/1053-5357(91)90019-P 
Färe, R.; Grosskopf, S.; Lovell, C. A. K. 1985. The Measurement of Efficiency of Production. Kluwer Nijhoff, Boston, MA. $216 \mathrm{p}$.

Farrell, M. J. 1957. The measurement of productive efficiency, Journal of the Royal Statistical Society, Series A (General), Part 3, 253-281. http://dx.doi.org/10.2307/2343100

Førsund, F. R.; Lovell, C. A. K.; Schmidt, P. 1980. A survey of frontier production functions and of their relationship to efficiency measurement, Journal of Econometrics 13(1): 5-25. http://dx.doi.org/10.1016/0304-4076(80)90040-8

Golany, B.; Yu, G. 1997. Estimating returns to scale in DEA, European Journal of Operational Research 103(1): 2837. http://dx.doi.org/10.1016/S0377-2217(96)00259-7

Hjalmarsson, L.; Odeck, J. 1996. Efficiency of trucks in road construction and maintenance: An evaluation with data envelopment analysis, Computers \& Operations Researche 23(4): 393-404.

http://dx.doi.org/10.1016/0305-0548(95)00047-X

Jahanshahloo, G. R.; Hosseinzadeh Lotfi, F.; Zohrehbandian, M. 2005. Notes on sensitivity and stability of the classification of returns to scale in data envelopment analysis, Journal of Productivity Analysis 23(3): 309-313. http://dx.doi.org/10.1007/s11123-005-2211-0

Jahanshahloo, G. R.; Soleimani-Damaneh, M. 2004. Estimating returns-to-scale in data envelopment analysis: a new procedure, Applied Mathematics and Computation 150(1): 89-98. http://dx.doi.org/10.1016/S0096-3003(03)00199-1

Jahanshahloo, G. R.; Soleimani-Damaneh, M.; Reshadi, M. 2006. On Pareto (dynamically) efficient paths, International Journal of Computer Mathematics 83(8-9): 631-635. http://dx.doi.org/10.1080/00207160601056099

Jain, S. S.; Aggarwal, S.; Parida, M. 2005. HDM-4 pavement deterioration models for Indian National Highway Network, Journal of Transportation Engineering ASCE 131(8): 623-631. http://dx.doi.org/10.1061/(ASCE)0733947X(2005)131:8(623)

Kerstens, K.; Vanden Eeckaut, P. 1999. Estimating returns-toscale using non-parametric deterministic technologies: a new method based on goodness-of-fit, European Journal of Operational Research 113(1): 206-214. http://dx.doi.org/10.1016/S0377-2217(97)00428-1

Khan, M. U.; Odoki, J. B. 2010. Establishing optimal pavement maintenance standards using the HDM-4 Model for Bangladesh, Journal of Civil Engineering 38(1): 1-16.

McMullen, C. C. 1986. Maintenance Activities Accomplished by Contract. NCHRP Synthesis 125, National Cooperative Highway Research Program, Transportation Research Board National Research Council, Washington, D.C. 42 p.

Raab, R. L.; Lichty, R. W. 2002. Identifying sub-areas that comprise a greater metropolitan area: the criterion of county relative efficiency, Journal of Regional Science 42(3): 579594. http://dx.doi.org/10.1111/1467-9787.00273

Ramanathan, K. V. 1985. A proposed framework for designing management control systems in not-for-profit organizations, Financial Accountability \& Management 1(1): 7592. http://dx.doi.org/10.1111/j.1468-0408.1985.tb00245.x

Rao, K. 1982. Managing State Highway Finance. NCHRP Synthesis of Highway Practice, 100. National Cooperative Highway Research Program, Transportation Research Board National Research Council, Washington, D.C. 23 p.

Rouse, P.; Chiu, T. 2009. Towards optimal life cycle management in a road maintenance setting using DEA, European Journal of Operational Research 196(2): 672-681. http://dx.doi.org/10.1016/j.ejor.2008.02.041
Rouse, P.; Putterill, M. 2000. Incorporating environmental factors into a highway maintenance cost model, Management Accounting Research 11(3): 363-384. http://dx.doi.org/10.1006/mare.2000.0133

Rouse, P.; Putterill, M. 2005. Local government amalgamation policy: A highway maintenance evaluation, Management Accounting Research 16(4): 438-463. http://dx.doi.org/10.1016/j.mar.2005.07.003

Rouse, P.; Putterill, M.; Ryan, D. 1997. Towards a general managerial framework for performance measurement: A comprehensive highway maintenance application, Journal of Productivity Analysis 8(2): 127-149. http://dx.doi.org/10.1023/A:1007743606303

Seiford, L. M.; Zhu, J. 1999a. Sensitivity and stability of the classifications of returns to scale in data envelopment analysis, Journal of Productivity Analysis 12(1): 55-75. http://dx.doi.org/10.1023/A:1007803207538

Seiford, L. M.; Zhu, J. 1999b. An investigation of returns to scale in data envelopment analysis, Omega 27(1): 1-11. http://dx.doi.org/10.1016/S0305-0483(98)00025-5

Soleimani-damaneh, M. 2009a. A fast algorithm for determining some characteristics in DEA, Journal of the Operational Research Society 60(11): 1528-1534. http://dx.doi.org/10.1057/jors.2009.72

Soleimani-damaneh, M. 2009b. An effective computational attempt in DDEA, Applied Mathematical Modelling 33(10): 3943-3948. http://dx.doi.org/10.1016/j.apm.2009.01.013

Soleimani-damaneh, M.; Reshadi, M. 2007. A polynomial-time algorithm to estimate returns to scale in FDH models, Computers \& Operations Research 34(7): 2168-2176. http://dx.doi.org/10.1016/j.cor.2005.08.004

Soleimani-damaneh, M.; Mostafaee, A. 2009. Stability of the classification of returns to scale in FDH models, European Journal of Operational Research 196(3): 12231228. http://dx.doi.org/10.1016/j.ejor.2008.05.020

Soleimani-damaneh, M.; Jahanshahloo, G. R.; Reshadi, M. 2006. On the estimation of returns to scale in FDH models, European Journal of Operational Research 174(2): 1055-1059. http://dx.doi.org/10.1016/j.ejor.2005.01.051

Soleimani-damaneh, M.; Jahanshahloo, G. R.; Mehrabian, S.; Hasannasab, M. 2010. Returns to scale and scale elasticity in the presence of weight restrictions and alternative solutions, Knowledge-Based Systems 23(2): 86-93. http://dx.doi.org/10.1016/j.knosys.2009.06.012

Tatari, O.; Skibniewski, M. 2006. Integrated agent-based construction equipment management: conceptual design, Journal of Civil Engineering and Management 12(3): 231236.

Thanassoulis, E.; Boussofiane, A.; Dyson, R. G. 1996. A comparison of data envelopment analysis and ratio analysis as tools for performance assessment, Omega 24(3): 229-244. http://dx.doi.org/10.1016/0305-0483(95)00060-7

Tone, K. 2002. A slacks-based measure of super-efficiency in data envelopment analysis, European Journal of Operational Research 143(1): 32-41. http://dx.doi.org/10.1016/S0377-2217(01)00324-1

Tone, K.; Sahoo, B. K. 2006. Re-examining scale elasticity in DEA, Annals of Operations Research 145(1): 69-87. http://dx.doi.org/10.1007/s10479-006-0027-6

Wei, C.-H.; Schonfeld, P. M. 1998. A research framework for cost-effective highway maintenance planning, Public Works Management \& Policy 2(4): 340-349. 
Yu, M.-M.; Lee, B. C. Y. 2009. Efficiency and effectiveness of service business: Evidence from international tourist hotels in Taiwan, Tourism Management 30(4): 571-580. http://dx.doi.org/10.1016/j.tourman.2008.09.005
Zhu, J. 2000. Further discussion on linear production functions and DEA, European Journal of Operational Research 127(3): 611-618.

http://dx.doi.org/10.1016/S0377-2217(99)00344-6

Gang LEE. PhD. Candidate at the Civil Engineering Department, National Taipei University of Technology, Taiwan, Republic of China. He is a member of Chinese Institute of Transportation, and Taiwan Efficiency and Productivity Society. His research interests include the Intelligent Transportation Systems, Transportation Economics and Management.

Ming-Miin YU. Professor at the Department of Transportation Science, National Taiwan Ocean University, Taiwan, Republic of China. He is a member of Eastern Asia Society for Transportation, Chinese Institute of Transportation, and Taiwan Efficiency and Productivity Society. His research interests include the Transportation Economics and Management, Logistics, particularly the Productivity and Efficiency Analysis in Transportation and Logistics.

Lung-Chuang WANG. Professor at the Civil Engineering Department, National Taipei University of Technology, Taiwan, Republic of China. He is a textbook referee of vocational school of National Institute for compilation and Translation, and a license's moderator of Taiwan Academy of Banking for Construction and Planning Acts. His research interests include the Construction Economics, Fuzzy Theory, Intelligent Transportation Systems and Decision Analysis. 